\title{
Impaired Asset Management and the Optimal Timing of Write-Down Decisions
}

\section{Gali Ingber and Avi Messica*}

The Graduate School of Business and Administration, The College of Management, Rishon Lezion, Israel

\begin{abstract}
Asset write-down refers to a reduction of an impaired asset's value on a firm's balance sheet. Impaired asset management has attracted much attention since the 2008 credit crunch crisis with respect to regulation, corporate and managerial ethics, capital market response and more. The common approach in past studies of write-downs based the decision-making process on agency-related reasoning. This paper presents a quantitative financial analysis of the optimal write-down timing of an impaired asset under different settings as well different managerial attitudes. We applied a conditional time-averaged value of a firm's stock price to model the manager's decision-making process and analyzed the optimal timing of write-down with respect to the capital market as well as management's expectations. Different exogenous settings of the optimal write-down timing such as impairment recovery rate and stock price return were analyzed. Moreover, a rational-type and behavioral type models of managers were also studied. Under most settings, our findings indicate that the common practice among managers, of write-down aversion, is optimal. However, counterintuitively, we found that under specific setting the optimal action is, on the contrary, to write down. Moreover, write-down decision is also dependent on the firm's stock price daily volatility. Managers of firms having stocks of high price volatility are in a favored position, decision-making wise, in comparison against manager of low volatility stocks.
\end{abstract}

Keywords: Financial management; Decision making; Optimal timing; Write-down

\section{Introduction}

Asset write-down is a reduction of the book value of a devalued asset, an action that is also referred to as mark-to-market valuation. Asset impairment often occurs when there are changes in regulation or during business climate declines. Asset write-down has been recognized as one of the most important risks for management as well as stock holders. For example, the 2008 crisis has revealed significant hidden risks that financial institutions and banks were exposed to when they experienced acute devaluation of real estate assets that were either directly or indirectly recognized on their balance sheets. Acquisition transactions present managers with a write-down dilemma when the value of the acquiree is impaired. Under the US regulation (GAAP), impaired assets must be recognized once there is evidence of a lack of recoverability of the asset's value. Furthermore, once impairment has been recognized it cannot be restored. In some other countries, as well as under the International Accounting Standards Board (IASB), companies can recognize recovery in the value of a written-down asset. Even when the impaired assets are destined for sale, they still must be written down to their fair value. Asset write-down has adverse effects on financial statements and ratios as well as on current income statement. On the balance sheet, written-down assets reduce stockholders' equity, increases the current and future fixed-asset turnover (due to lower fixed assets) and results in higher debt-to-assets ratio. All these have a negative impact on the firm's stock price hence the reluctance of managers to write down devalued assets.

Asset write-down aversion was empirically explained by agencybased arguments. Given that managers are paid to create value that is reflected in the stock price, then write-down negatively affects the stock price and indicates of managerial incompetence as well as failure to allocate capital effectively. Former researchers have pointed out that write-down aversion is correlated with the fact that managers are measured by their firm's stock performance. The capital markets are well aware of this aspect and might penalize the stock price even before write-down is practiced. The recent credit crunch and the burst of the
American real estate bubble have brought up to the fore the important issue of write-down timing. Therefore, asset impairment presents the manager with a difficult decision making. On one hand, writing-down too soon might results in an unnecessary negative impact on the firm's stock price that in the face of potential value recovery might not be the optimal decision to make. On the other hand, a delayed write-down might lead to excess price penalty due to an over-reaction of the capital market. This optimization problem is intensified in the presence of timing uncertainty since managers cannot tell if and when the capital market learns about the asset's impairment or what is the impairment recovery rate.

\section{Literature Review}

Until 2007 (US FASB-157), write-downs were purely discretionary and there was no clear guidance of what comprises an impaired asset. Therefore, past studies are ambiguous about the market impact of write-downs. Healy [1] claimed that firms perform asset write-downs in years of lower earnings in order to increase the likelihood of future earnings growth. This view was also supported by Elliot and Shaw [2] as well as Zucca and Campbell [3] who examined discretionary writedowns and found that they were more prevalent among firms of low profitability, firms with earnings below expectations, or firms that had lower return on assets. They concluded that managers of such firms have the incentive to write-down assets in expectation that it will result in higher future returns on assets and equity. Heflin and Warfield [4]

*Corresponding author: Avi Messica, The Graduate School of Business and Administration, The College of Management, P.O.B 25073, 7 Yitzhak Rabin Blvd., Rishon Lezion 75190, Israel, Tel: 97239634013; E-mail: avi1m@colman.ac.il

Received October 29, 2017; Accepted November 27, 2017; Published December 04, 2017

Citation: Ingber G, Messica A (2017) Impaired Asset Management and the Optimal Timing of Write-Down Decisions. Ind Eng Manage 6: 230. doi:10.4172/21690316.1000230

Copyright: (C) 2017 Ingber G, et al. This is an open-access article distributed under the terms of the Creative Commons Attribution License, which permits unrestricted use, distribution, and reproduction in any medium, provided the original author and source are credited. 
also supported the hypothesis that managers usually withhold writedown for a rather prolonged period and recognize it over poorer earnings' years in anticipation for future improvement.

Strong and Meyer [5] found that the timing of asset devaluation over the period of management turnover or poorer business performance reveals how management exploits impairment losses to maneuver a big rise in following earnings, which might result in a larger bonus or other compensation. Chen [6] described how firms with higher earnings appear to defer losses from current impaired assets across continuous years, but firms with negative earnings move ahead to recognize losses from asset devaluations. This behavior of recognizing write-down early or late is consistent with Strong and Meyer's conjecture. Francis et al. [7] concluded that discretionary write-down often occurs upon change of management. They suggested that either management tries to improve investors' perceptions of the future financial performance of the firm or that management tries to lay down a new accounting foundation for future years.

Bartov et al. [8] studied the impact of significant write-downs (averaging about $20 \%$ of firms' market values) on the stock's price response. They found that price declines preceded write-down announcements. Their findings suggest that disclosure standards may not be sufficient to allow market agents to understand the economic consequences of the write-down and that market response exhibited excessive mispricing. Aboody [9] also studied whether recognition and disclosure had equivalent price impact on the stocks of companies in the oil and gas sector. Managers can signal important information when writing down assets that they manage. He noted that empirical studies indicated that whether an asset was recognized or disclosed influenced the perception of investors that use financial statements as investment analysis tool. He concluded that the stocks' price reaction of firms that recognized losses were negative.

Srinivasan and Bublitz [10] investigated the impact of recognized, unexpected, write-downs on market's reaction relative to other recognized unexpected costs or expenses. They found that market's reaction, on average, was positive regarding recognized unexpected asset write-downs as opposed to the reaction regarding recognized unexpected costs of goods sold for example. Sunder [11] indicated that managers decide to write-down during a downturn in the industry. Managers attribute the write-down, as well as poor business performance, to the weak market and not to themselves. Kwon et al. [12] examined 47 firms that voluntarily disclosed write-down information in their annual reports and found that they experienced more positive market reaction than firms that delayed such disclosure. Recently Prakash [13] analyzed write-down decisions of firms during recessions and found that for a given decline in sales, the probability of writing down assets in recession times was higher than during expansion. Peetathawatchai and Acaranupong [14] showed that management opportunistically recognizes an impairment loss in order to smooth earnings when earnings increase which resulted in a misrepresentation of the value of the firm.

The rich literature on the issue indicates of a complex as well as time-dependent managerial behavior that intertwines financial, i.e. stock performance, considerations with agency-related considerations. Most of the past research has focused on empirical as well as descriptive analysis. While there are many empirical studies with focus on managerial behavior and motives, less effort was devoted to a quantitative analysis and moreover to the optimal timing of asset writedown [15].
This paper presents a model that includes both the financial and behavioral aspects of managers when dealing with asset write-down. To the best of our knowledge, this is the first effort to analyze the optimal timing of asset write-down as well as to examine the optimal managerial practices that can be derived via a quantitative model. We present a model where a firm's manager is required to make a decision if and when to write down an impaired asset under the premise that write-down has a negative impact on the stock's price. The manager seeks to maximize the firm's stock price but does not know if and when the market learns about the bad news. An excessive negative price impact, due to the market's over-reaction to bad news upon discovery, was modeled. Finally, we considered potential recovery of the impaired asset, over time, and analyzed scenarios of stock price growth or decline in parallel. The main contribution of this paper is by providing a new angle that augments the existing view of write-down decision making as well as delivering new insights about the optimal timing of writedown. We present and discuss new factors that are associated with the decision making such as stock's price daily volatility, impairment recovery rate and the expected time of market discovery.

The rest of this paper is organized as follows. In the following section we present the model and its results. In section four we discuss the results as well as managerial implications and in the last section we provide a summary [16].

\section{Model Description}

An overview of the model is as follows. Upon the occurrence of asset impairment, the manager has two possible courses of action. She can either write down the value of the asset, bearing the risk of a negative impact on the stock's price, or she can delay the decision in anticipation that the impaired value will partially, or completely, recover over time. However, if the latter decision is made, she risks that if the capital market finds out about the impairment it will respond disproportionality to the bad news, resulting in an excessive negative price impact. Therefore, the conditional time-averaged impact of the impaired asset on the stock's price was required. In addition, the model was extended to include two types of managers. The first type, whom we refer to as simplistic (rational) manager, considers only the direct negative impact on the stock's price. The second type, a behavioral manager, takes into account a potential "price penalty" inflicted by the capital market for delaying the write-down decision. To account for managerial uncertainty in the face of a random discovery time by the market, a probability distribution function of the discovery time was introduced.

\section{Optimal timing: A simplistic manager}

Assign $t=0$ as the time of asset impairment. Given an arbitrary probability distribution $f(u)$ of the market's discovery time, the conditional time-averaged stock price, $P(t)$, at time $t \geq 0$ is as follows:

$$
\langle P(t)\rangle=\int_{t}^{\infty} \frac{P_{0} e^{g u}-\Delta e^{-r_{C} u}}{1-F(u)} f(u) d u
$$

Here, $F(t)=\int_{0}^{t} f(u) d u$ is the cumulative probability distribution up to time $t$.

It is the managers' objective to maximize $\langle\mathrm{p}(\mathrm{t})\rangle .\langle\mathrm{p}(\mathrm{t})\rangle$ is the average stock price conditioned on that no discovery has taken place until time $t$. The price $p(t=0)=P_{\mathrm{o}}$ stands for the stock price at the time of impairment. The expected stock's price impact (i.e., price drop) due to the negative news is designated as $\Delta$. It is assumed that is constant and implies the maximum price impact. The rate at which impairment 
recovery takes place is designated $r_{c}$ and the firm's stock return is g. No specific probability distribution function is assumed a priori. A constrained maximization of $\langle\mathrm{p}(\mathrm{t})\rangle$ results in the optimal write-down time under the requirement that $\mathrm{p}(\mathrm{t}) \geq 0$ (stock price cannot assume negative values). Therefore, any admissible solution of $\langle\mathrm{p}(\mathrm{t})\rangle$ must meet the following constraint:

$$
P_{0} e^{g t}-\Delta e^{-r_{c} t} \geq 0
$$

The time derivative of (1) is

$$
\frac{d\langle P(t)\rangle}{d t}=-\frac{P_{0} e^{g t}-\Delta e^{-r_{c} t}}{1-F(t)} \times f(t)=0
$$

Note that $1-F(t)>0$ and is surely positive for any $t>0$. Theoretically speaking, four scenarios of stock's price movement and impairment recovery are possible. However, assuming that $\Delta$ is the maximum stock's price impact and that potential recovery is possible. We excluded from the analysis a treatise of increase in $\Delta$ via a negative (impairment) recovery rate $r_{c}$. Therefore, there are only two possible price-movement scenarios to analyze in conjunction with impairment recovery. Namely, a growing stock price (i.e., $g>0$ ) or a declining price where $\mathrm{g}>0$.

\section{Stock price growth: A simplistic approach}

Obviously the most desired scenario from managerial perspective is one in which the stock price rises as well as the value of the impaired asset. This scenario is comprised of positive price growth and impairment recovery rates $\left(\mathrm{g}>0, \mathrm{r}_{\mathrm{c}}>0\right)$.

Under this setting, the time-derivative, eqn. (3) attains its maximum when $f(t)=0$ that requires $\lim _{t \rightarrow \infty} f(t) \rightarrow 0$, at time $t \rightarrow \infty$. Therefore, under this setting, the optimal timing for a simplistic manager is to delay the write-down decision as much as possible. Importantly, this result is independent of the specific form of $f(u)$. Maintaining such policy results in a declining impact of the impaired asset on the stock price at future times since the impact of the subtracted term in $P_{0} e^{g t}-\Delta e^{-r_{C} t}$ diminishes over time due to impairment recovery. Therefore, the observed write-down managerial practice can be well explained by a quantitative model as well. Namely, managers delay write-down decisions in anticipation for such optimistic scenario to materialize. Our finding augments, modeling-wise, the interpretations and conclusions that were made by past research [2-4] as well as others.

\section{Stock price decline: A simplistic approach}

A more challenging scenario from the manager's perspective is the case of stock price decline (remember, $r>0$ i.e., negative stock returns $\mathrm{g}>0$. Designate the optimal write-down time as $t^{*}$. Then the derivative eqn. (3) attains its maximum by requiring that $P_{0} e^{g t}-\Delta e^{-r_{c} t}=0$ constrained by $\Delta \leq P_{0}$.

Under this setting, the manager faces two decision making subscenarios where the ratio, eqn. (4) depends on the difference $|\mathrm{g}|-r$.

$$
P_{0} e^{g t} / \Delta e^{-r_{C} t}
$$

For the case of $|\mathrm{g}|>r_{c}$ the optimal write-down time is to immediately write-down the impaired asset. If not doing so, then effectively the relative impact on the stock price, even though recovery takes place, increases over time due to stock's price erosion taking place at a rate faster than the recovery rate. Therefore, whenever the stock's price growth rate is negative and larger in magnitude than the impairment recovery rate, the optimal timing would be to write down. The more the manager delays her decision, the harder the impact the stock price will suffer.

Under the second setting where the stock return is negative but maintains $|\mathrm{g}|<r$, the optimal timing would be to delay write-down as much as possible. In this scenario the stock price moves up at a faster rate than the recovery rate and therefore there is double action, over time, of reducing the price impact of the impaired asset. Figure 1 presents a decision space of the relative price impact plotted against the value of $g+r$ for different delays. In case of negative $g+r_{c}$ values where $\mathrm{g}<0$ and $|\mathrm{g}|<r$, the optimal policy is to write down the value of the impaired asset since its impact on the stock price will increase with the delay. The more significant the stock's price erosion is (i.e., the more negative $g+r_{c}$ is, the difference between the recovery rate and the stock's return), the greater is the negative impact. The increase in impact, despite the recovery in the value of the asset, results in due to deterioration in the stock price. In contrast, in case of a positive stock return the impact will decrease over time and the optimal policy is to delay the write-down decision. In this scenario, the more the decision is delayed the less sever is the impact on stock price.

To the best of our knowledge such scenario has not been considered in the literature in the past and papers that pointed out that price declines preceded write-down announcements made no such subtle distinction (i.e., between the $|\mathrm{g}|>r$ vs. $|\mathrm{g}|<r$ scenarios). Our modeling indicates that simplistic managers should consider three possible scenarios rather than the two that are reported in the literature. Specifically, in case of a declining stock price the decision-making process should fork into two choices. Managers can quantitatively analyze, or estimate, the state that their firm is at, i.e., $|\mathrm{g}|>r$ or $|\mathrm{g}|<r$, and make their writedown decision accordingly.

\section{Optimal timing: Behavioral manager}

At any time, designated as $t_{1}\left(t_{1}>0\right)$, the manager takes into account that upon delaying the write-down decision she risks a stock price penalty sell-off $\delta_{p}$ that might take place over the period of time between $t_{1}$ and some unknown future time $t>t_{1}$. A stock sell-off was modeled by adding a constant price penalty, designated $\delta$, to extend expression (1). Constrained maximization was carried out under the requirement that $\Delta+\delta_{\mathrm{p}} \leq P_{\mathrm{o}}$ (i.e., price non-negativity). Under this setting then:

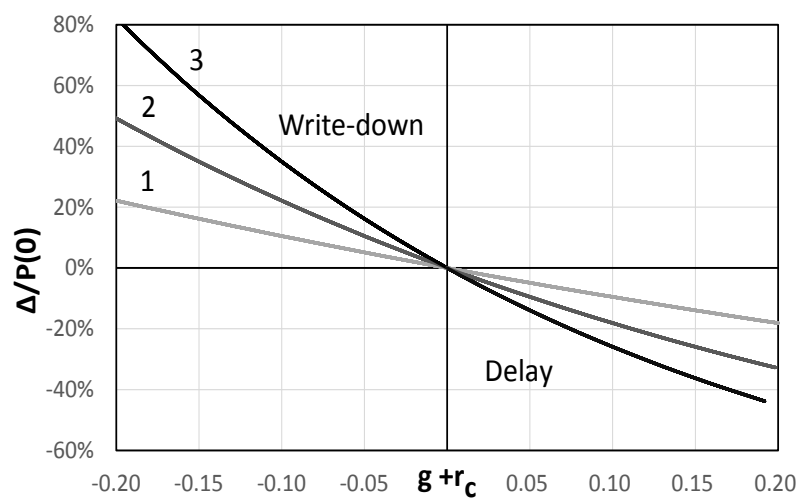

Figure 1: The relative impact (percentage) $4 / P_{0}$ plotted against the value of $g+r_{c}$ for different delay times (light gray is a one-year delay, dark gray is two years, three years delay is the black line). Negative $g+r_{c}$ values refer to negative stock return that maintains $\lg \mid<r$. Positive $g+r$ refers to stock price growth. For negative $g+r_{c}$ values the optimal policy is to write down, otherwise, to delay the decision. 


$$
\langle P(t)\rangle=\int_{t_{1}}^{t} \frac{P_{0} e^{g u}-\Delta e^{-r_{c} u}-\delta_{P}}{1-F(t)} f(u) d u+\int_{t}^{\infty} \frac{P_{0} e^{g u}-\Delta e^{-r_{c} u}}{1-F(t)} f(u) d u
$$

The notation of eqn. (5) is the same as of eqn. (1) with the extension that was described above. The first term on the right-hand side of eqn. (5) is the conditional averaged price in case of market discovery at time between $t_{1}$ to $t>t_{1}$ in which the stock suffers price-penalty $\delta_{p}$. The second term on the right-hand side of eqn. (5) is the conditional averaged price after which discovery has taken place, hence the absence of the penalty term. Since the impact of the stock price penalty is constant it does not affect the time derivative of eqn. (5) and condition eqn. (3) is applicable for this case as well. Therefore, avoiding write-down is optimal even in the presence of price penalty as well as irrespectively of the values of $r_{c}$ and g. Meaning, as long as the price penalty is a one-time event then avoiding write-down is optimal. Moreover, the higher the stock price is and the lower the impairment impact is (possibly if some recovery has taken place already by time $t_{1}$ ), the weaker is the price penalty impact upon a future market's discovery. Consideration of the so-called "Capital market punishment" in the managerial write-down decision making process was hardly addressed by former researchers. Our findings indicate that managers should be indifferent to "capital market punishment" in their decision-making process and focus on stock return and impairment-recovery-rate as quantitative measures for decision making.

\section{Impairment recovery period}

The reader has already noticed that an important aspect of the write-down's timing decision is the uncertain recovery period as well as the amount of recovery that will render the impairment insignificant. An estimate of the recovery period can provide managers additional information for decision making. It is plausible to assume that when the impairment's impact on the stock price is roughly equivalent to the stock price daily volatility, then the capital market is indifferent to the impaired value. Designating the random time of full recovery as $t_{\mathrm{R}}$ and denoting $\sigma_{\mathrm{p}}$ as the stock's daily return volatility (percentage-wise), then the impairment recovery period can be estimated from the following estimate:

$$
\frac{\Delta e^{-r_{C} t_{R}}}{P_{0} e^{g t_{R}}} \leq 2 \sigma_{P}
$$

The factor of two accounts for a 95\% confidence interval (assuming an approximate normally distributed daily returns) to reflect the daily volatility span that stock holders experience.

Eqn. (6) results in:

$$
t_{R}=-\frac{1}{r_{C}+g} \times \ln \left(\frac{2 \sigma_{P}}{\Delta / P_{0}}\right)
$$

Here we consider a scenario where $\mathrm{g}>0$ and $\mathrm{r}_{c}>0$ under the requirement that $\sigma_{P} \leq \Delta / P_{0}$. The recovery period is inversely proportional to the sum of the impairment recovery and growth rates. The faster both the growth and recovery rates are, the shorter is the recovery period. Obviously, when the stock price grows in time then the price impact of asset impairment diminishes. Recovery is also dependent on the daily price volatility. Obviously, the higher the price impact is, the longer is the expected recovery time. However, the effect of high price volatility is of expediting recovery (in comparison against low price volatility).

The S\&P500 daily return volatility is $\sigma_{\mathrm{P}}=1.2 \%$ (Yang and Tsoi, 2016) and individual stocks volatility is quite often higher and in the 2\%-2.5\% range (Arratia, 2014). Figure 2 illustrates the impact of stock's price volatility on the recovery period plotted for illustration for $\mathrm{g}=8 \%$ and $\mathrm{r}_{\mathrm{c}}=5 \%$ (i.e., annual stock growth and recovery rates) as well $\Delta / P_{0}=20 \%$. Note that managers of firms with high volatility stocks are in a favored position in comparison against managers of firms less volatile stocks. Namely, the more volatile the firm's stock is, the faster is the recovery period. Managers of highly volatile stocks, having a relatively short recovery period, can therefore delay the write-down decision in the face of fast recovery. Such option is less available for managers of low volatility stocks with relatively long recovery period.

\section{Timing uncertainty}

To estimate the temporal uncertainty that the manager experiences, a gamma distribution function $\gamma(\alpha, \beta)$. Here, $\alpha$ is the number of events in a given time interval for a Poisson process characterized by a mean time between events of $1 / \beta$. The mean time of occurrence of $\alpha$ events is $\alpha / \beta$. In case of write-downs there is only one event to consider (the market discovery about the asset's impairment) hence $\alpha=1$. Therefore, the probability distribution function takes the form of exponential distribution $f(u)=\beta e^{-\beta U}$. Plugging $f(u)=\beta e^{-\beta U}$ into eqn. (6), the recovery time is extracted via the conditional average of $\frac{\Delta e^{-r_{c} t}}{P_{0} e^{g t}}$ between a decision time $\mathrm{t}>0$ and time $\mathrm{t}_{1}>\mathrm{t}$ where impairment discovery occurs results in the following expression:

$$
\left.\left\langle\frac{\Delta e^{-r_{C} t}}{P_{0} e^{g t}}\right\rangle\right|_{\left[t, t_{1}\right]}=\frac{\int \beta e^{-\beta u} \frac{\Delta e^{-r_{C} u}}{P_{0} e^{g u}} d u}{e^{-\beta t}} \leq 2 \sigma_{P}
$$

Eqn. (8) results in the following expression for the recovery time $t_{1}$ as function of the decision time $t>0$.

$$
t_{1}=\frac{\beta}{r_{C}+g+\beta} \times\left\{t-\frac{1}{\beta} \ln \left[1-\frac{2 \sigma_{P}}{\Delta / P_{0}}\left(1+\frac{r_{C}+g}{\beta}\right)\right]\right\}
$$

Figure 3 illustrates the impact of the market's mean discovery time on management's decision horizon (Figure 2 values were uses) plotted for a firm with a stock's daily price volatility of $\sigma \mathrm{P}=2 \%$. The plot displays the expected time of market discovery on periodic review

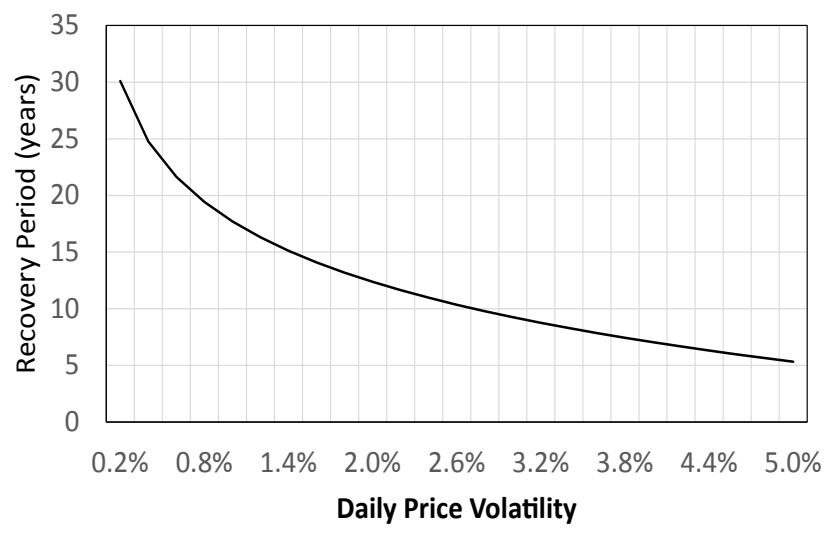

Figure 2: The impaired asset recovery period (in years) plotted against daily price volatility for $\Delta / P_{0}=20 \%, g=8 \%, r_{c}=5 \%$ Highly volatile stocks, e.g. $\sigma_{\mathrm{p}} \geq$ $3.5 \%$, allow managers to option to delay write-down in anticipation for fast recovery. 
times (on a quarterly basis) of the write-down decision. Figure 3 illustrates that, for a given mean discovery time, the farther a delayed write-down decision is not discovered, the better are the chances are that it won't get discovered. These dynamics results in from the positive stock's return, impaired asset recovery and the exponential decay of the market's discovery probability.

The multiple plots illustrate the expected time-to-discovery on quarterly review times $(90,180,270,360$ days) starting at the impairment time $t=0$. The expected time-to-discovery lengthens as time passes with no discovery.

\section{Discussion}

Our findings, for both the simplistic and behavioral managers' models, are agnostic to the probabilistic nature of the problem. It is a common practice in decision theory to use probability distribution functions such as gamma, beta or even normal distribution in some specific cases. The analysis presented in above sections is independent of the specific functional form of the discovery time's probability distribution and as such is generic. Our model-based findings corroborate the empirical evidence about write-down decisions made by managers. Table 1 summarizes the main findings of this paper for the decision space that was studied.

Following the analysis, we can also draw a generic conclusion about the write-down timing decision among firms of different industrial sectors. For example (Figure 2), managers of firms in highly volatile (stock price) sectors such as high-technology, bio-technology and the like can afford to delay a write-down decision in anticipation for a relatively fast recovery while managers of companies in low volatility sectors such as utilities, consumer staples and the like are less likely to be able to do so due to a long recovery period. Noteworthy, timing of a

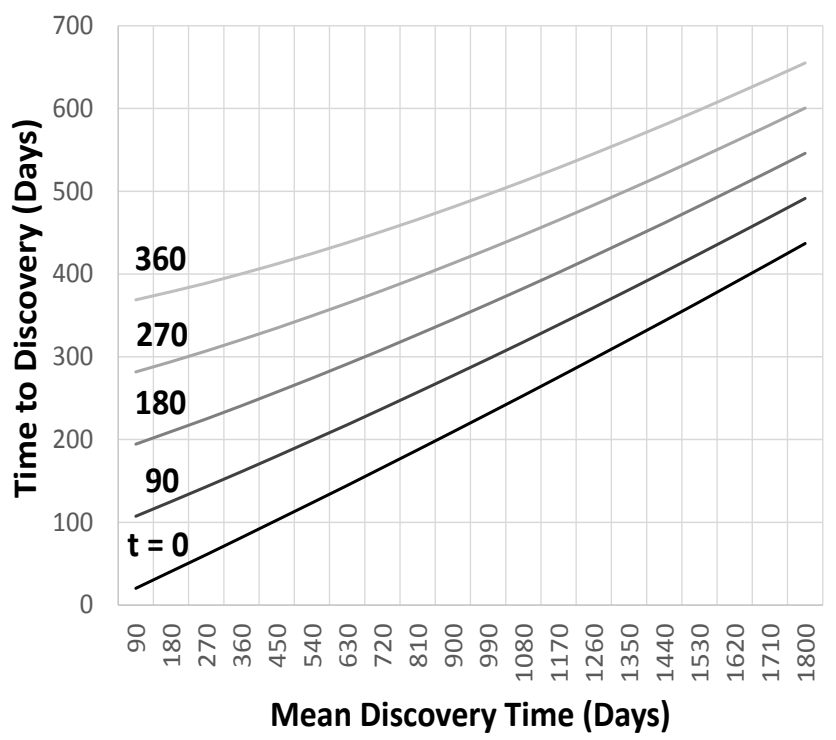

Figure 3: Decision-time horizon plotted vs. the market's mean discovery time $1 / \beta$.

\begin{tabular}{|c|c|c|}
\hline & $|\mathbf{g}|>r_{c}$ & $|\mathbf{g}|<r_{c}$ \\
\hline $\mathbf{g} \geq 0$ & No write down & No write down \\
\hline $\mathbf{g}<0$ & Write down & No write down \\
\hline \multicolumn{3}{|c|}{ Table 1: Optimal write-down decision. }
\end{tabular}

write-down decision could be firm-specific as well for firms belonging to the same industrial sector.

Eqn. (9) indicates that the recovery time is linked with the decision time, $t \propto t$. Obviously, the longer the firm holds onto the bad news then the higher is the probability that it will not get discovered since impairment recovery takes place over the withholding time. Modelwise, this is a consequence of the exponential - decaying - nature of the discovery probability as well as the positive stock's growth and asset's recovery rates. Therefore, in most cases, apart from one specific case, managers' write-down aversion can be justified on a financial reasoning in tandem with agency-related considerations. To illustrate our findings very simply, consider for example (see the analysis in the above sections) an average discovery time of 360 days, that impairment recovers at an annual rate of $4.6 \%$ and an annual stock return of $10 \%$. Further assume that the firm's stock daily volatility is $2 \%$ and the write down impact is $\frac{\Delta}{P_{0}}=20 \%$ - as studied by Under these settings, our model's (daily) parameters are $\beta=\frac{1}{360}, r_{C}=0.000128(4.6 \%$ annually) and $\mathrm{g}=0.000277$ ( $10 \%$ annually) [8].

Plugging these values into eqn. (9) it can be approximated as follows:

$$
t_{1} \cong \frac{t+44}{1.15}
$$

Approximation, the eqn. (10) is a more concise representation of a typical curve such as those depicted in Figure 3 that clearly demonstrates that the later the decision time $t$ is, the longer the expected discovery time is. Practically speaking, the more the manager is "getting away" with avoiding write-down the better her prospects are, probability wise, of not writing down.

\section{Conclusion}

Write-down decision making was analyzed via a probabilistic financial model. An analysis of the optimal write-down timing of an impaired asset was carried out under different settings as well different managerial attitudes. We modeled the conditional time-averaged value of a firm's stock price and analyzed the optimal timing of write-down with regard to the capital market as well as management's expectations. Under most settings, the common practice among managers, of writedown aversion, is optimal and may be justified on financial grounds on top of the common view of agency-related reasoning. However, we found that in a scenario where the firm's stock yields a negative return there is a fork of decision making where if the stock's negative return outweighs (in magnitude) the impairment recovery rate then the optimal decision is to write-down. Such distinction was not made in past research. Moreover, we found that the firm's stock daily price volatility has impact on the timing decision and therefore write-down timing decision is industrial-sector-dependent and could be firmspecific as well. This paper provides additional insight that augments the current understanding of asset impairment management and write-down timing.

\section{References}

1. Healy $P$ (1985) The effect of bonus schemes on accounting decisions. Journal of Accounting and Economics 7: 85-107

2. Elliot J, Shaw W (1998) Write-offs as accounting procedure to manage perceptions. Journal of Accounting Research 26: 91-119

3. Zucca L, Campbell D (1992) A closer look at discretionary write-downs of impaired assets. Accounting Horizons 6: 30-41 
Citation: Ingber G, Messica A (2017) Impaired Asset Management and the Optimal Timing of Write-Down Decisions. Ind Eng Manage 6: 230. doi:10.4172/2169-0316.1000230

Page 6 of 6

4. Heflin E, Warfield T (1997) Managerial discretion in Accounting for Assets Write Offs. Working. Paper, University of Wisconsin-Madison 1997.

5. Strong JS, Meyer JR (1987) Asset Write-downs: Managerial Incentives and Security Returns. The Journal of Finance 42: 643-661

6. Chen K (1991) The timing of asset write-downs in the oil and gas industry: 1985-1986. Petroleum Accounting and Financial Management Journal 10: 157-169.

7. Francis J, Hanna JD, Vincent L (1996) Causes and Effects of Discretionary Asset Write-Offs. Journal of Accounting Research 34: 117-134

8. Bartov E, Lindahl FW, Ricks Stock WE (1998) Price behavior around announcements of write-offs. Review of Accounting Studies 3: 327-346

9. Aboody D (1996) Recognition versus disclosure in the oil and gas industry. Journal of Accounting Research 34: 21-32

10. Srinivasan R, Bublitz BO (1996) An empirical analysis of the impact of asset write down disclosures on stockholder wealth. Quarterly Journal of Business and Economics 35: 32-47
11. Sunder S (2002) Theory of accounting and control. Cincinnati, Ohio: SouthWestern College Publishing.

12. Kwon SS, Sungsoo K, Gaber BG (2008) Voluntary asset write-downs of SFAS 121: early adopters vis-a-vis late adopters. International Journal of Accounting and Finance 1: 83-105.

13. Prakash R (2010) Macroeconomic factors and financial statements: asset write downs during recessions.

14. Peetathawatchai $P$, Acaranupong $K$ (2012) Are impairment indicators and losses associated in Thailand? Journal of Financial Reporting \& Accounting 10: $95-114$

15. Yipeng Y, Allanus T (2016) A Level Set Analysis and A Nonparametric Regression on S \& P 500 Daily Return, Int J Financial Stud 4: 3-8

16. Arratia A (2014) Computational Finance, Statistics of Financial Time Series, Chapter 2: 37-70, France, Paris: Atlantis Press - Springer 